\title{
Almadén en la España del siglo XVII. Crisis de producción de azogue y soluciones propuestas
}

\section{Almadén in $17^{\text {th }}$-century Spain. Crisis of production of quicksilver and proposed solutions}

\author{
María SilvestRe MADRID \\ Universidad de Castilla-La Mancha \\ maria.silvestre@uclm.es \\ Emiliano Almansa Rodríguez \\ Universidad de Castilla-La Mancha \\ emiliano.almansa@uclm.es
}

Fecha de recepción: 24-01-2018

Fecha de aceptación: 24-04-2018

\begin{abstract}
RESUMEN
A mediados del siglo $\mathrm{XVI}$, la mina de azogue de Almadén adquirió una gran importancia debido al descubrimiento del método industrial de la amalgamación para los minerales de plata de baja ley. Los accidentes, enfermedades y el impago de salarios hicieron que el trabajo de minero no fuera atractivo para los forasteros, de modo que faltaban brazos para dar la producción de azogue necesaria para abastecer a las minas americanas de plata. En el siglo XVII, el Consejo de Hacienda intentó solucionar el problema de las consignaciones económicas, lo que resultó harto difícil en una España con graves dificultades financieras y, por otra parte, trató de conseguir mano de obra para la mina, fuera forzada, esclava o procedente del repartimiento de pueblos cercanos.
\end{abstract}

PALABRAS CLAVE: Almadén, azogue, siglo XVII, mineros, repartimiento.

\section{ABSTRACT}

In the middle of the 16th century, the Almadén quicksilver mine acquired considerable importance due to the discovery of the industrial method of amalgamation of low-grade silver ores. Accidents, diseases and unpaid wages made mining work unattractive to outsiders, so manpower was needed for the quicksilver production necessary to supply American silver mines. In the 17th century, the Finance Council attempted to solve the problem of economic consignments, which was very difficult in a Spain with serious financial difficulties and, meanwhile, tried to obtain workers for the mine, be they forced, enslaved or from the repartimiento of nearby villages.

KEY WORDS: Almadén, quicksilver, 17th century, miners, repartimiento. 


\section{INTRODUCCIÓN}

Antes de la llegada de los romanos a Hispania, ya era conocido nuestro país por su extraordinaria riqueza metalífera, si bien fue el pueblo romano el que más explotó sus yacimientos minerales de oro, plata, plomo y bermellón ${ }^{1}$, entre otros. Restos de labores mineras romanas han aparecido en lugares tan distantes como Las Médulas (oro), en León; Hiendelaencina (plata), en Guadalajara; Las Cuevas (bermellón), cerca de Almadén; Hellín (azufre), en Albacete; y las de Almodóvar (Ciudad Real), Diógenes (Valle de Alcudia), Alcaracejos (Córdoba), Guadalcanal (Sevilla), Linares (Jaén) y Cartagena, en las cuales obtenían plomo y plata ${ }^{2}$. En algunas de ellas los pozos mineros romanos llegaron a alcanzar los 200 metros de profundidad y, al igual que sucedería siglos después, la falta de mano de obra libre condujo en aquella época a la utilización de forzados y esclavos, ya que las condiciones de trabajo eran muy duras. No obstante, ya en el siglo II comenzó a haber en las explotaciones mineras romanas más hombres libres que forzados y esclavos.

A diferencia de la minería romana, hay pocos datos concernientes a la minería medieval en España. Sin duda que los visigodos explotaron algunos de sus yacimientos minerales, pero es incuestionable que hubo un descenso en la producción respecto a la época romana. Lo mismo sucedió con la minería española durante el dominio musulmán, si bien las fuentes escritas son en este caso más abundantes, aunque poco fiables, como cuando el historiador Al-Idrisi afirma que la mina de azogue de Almadén tenía unos 250 metros de profundidad y en ella trabajaban más de mil mineros. El término tan común de almadenes hace referencia sin duda a labores mineras árabes, sobre todo en Sierra Morena. Además de Almadén, de donde extraían el precioso azogue, hay explotaciones árabes en diversos términos de Sevilla, como Guadalcanal y Constantina; de Córdoba, como Hornachuelos, Obejo y Cerro Muriano; de Jaén, como Linares y úbeda; y también en el Reino de Granada ${ }^{3}$.

A medida que la Reconquista fue avanzando, las explotaciones mineras árabes pasaron a manos cristianas, adquiriendo mayor importancia las minas de hierro, así como las ferrerías. En esa época de importante actividad guerrera, la fabricación de armas aumentó, lo que generó un incremento de la demanda de cobre, estaño, hierro, salitre y azufre. Estos dos últimos combinados con el carbón forman la pólvora, la cual ya se producía en el reino de Murcia hacia 1367. También la mina de Almadén fue tomando mayor importancia a medida que transcurría la Edad Media, ya que además de bermellón, se producían azogue y solimán ${ }^{4}$. El principal uso del primero de ellos era la pintura artística, el azogue se utilizaba sobre todo para la medicina y la alquimia, y el solimán, que es un cloruro de mercurio, se usaba primordialmente para curtir el cuero. Una parte del azogue producido en Almadén era enviado fuera de España, a través de comerciantes genoveses, quienes lo hacían llegar a las minas de Sudán y Etiopía, donde lo usaban para amalgamación de sus menas de oro. Cada vez hay más documentos que prueban de manera fehaciente que ya en los siglos XII y XIII, tanto en China como en el nordeste de África, era conocido el poder amalgamador

1 Decimos bermellón y no mercurio porque los romanos estaban más interesados en aquel, con el cual fabricaban pintura artística de enorme valor en aquella época.

2 J. Sánchez Gómez, De minería, metalurgia y comercio de metales. La minería no férrica en el reino de Castilla, 1450-1610, Salamanca, Universidad de Salamanca e Instituto Tecnológico GeoMinero de España, 1989, pp. 46-61.

3 Ibidem, pp. 68-77.

4 A. Matilla Tascón, Historia de las minas de Almadén, Vol. I: Desde la época romana hasta el año 1645, Madrid, Consejo de Administración de Minas de Almadén y Arrayanes, 1958, p. 13. 
del mercurio; todo ello sin querer restar mérito a Bartolomé de Medina, quien lo convirtió en un proceso industrial de primer orden en la mina de plata de Pachuca (virreinato de Nueva España) $)^{5}$.

El objetivo de este artículo es el estudio de una de las soluciones propuestas por el Consejo de Hacienda para lograr suficiente mano de obra para las labores subterráneas de la mina de azogue de Almadén en la España del XVII. A mediados del siglo XVI, la producción de Almadén comenzó a incrementarse debido a que en las minas de plata americanas se necesitaba el azogue para el beneficio de los minerales de baja ley. Como en aquella época no había bastantes forasteros que quisieran asentarse en Almadén para trabajar en las labores subterráneas, hubo de recurrirse a la mano de obra forzada, pero ni aun así hubo suficientes brazos para la explotación del yacimiento ${ }^{6}$. A mediados del siglo XVII, la situación se había agravado de forma considerable, pues las dificultades económicas de la Corona impedían que llegaran las necesarias consignaciones económicas para el laboreo minero y la paga de los operarios ${ }^{7}$. Por otra parte y a pesar de los constantes intentos de los superintendentes y administradores de la mina, la Corona no enviaba los forzados prometidos, ya que el remo en las galeras era un destino prioritario por los continuos ataques de turcos y berberiscos; tampoco había dinero para comprar todos los esclavos necesarios, y los moriscos, quienes habían sido en algunas ocasiones mano de obra obligada en el siglo XVI, sobre todo después de la sublevación de Las Alpujarras, habían sido ya expulsados de España por Felipe III en 1609. A mediados del XVII, el conde de Molina, miembro del Consejo de Hacienda y superintendente de la mina, propuso traer a Almadén peones de pueblos cercanos para que trabajasen en las labores subterráneas. No recibirían ningún salario, pero a cambio sus pueblos de origen se verían favorecidos con exenciones militares, como no aportar soldados ni bastimentos para el ejército. Este es un tema poco tratado en la historiografía de Almadén a diferencia de la mano de obra forzada, la cual ha sido estudiada sobre todo por los autores ya citados. Además, en este estudio se compara este repartimiento con los llevados a cabo en América colonial, como los ocurridos en las grandes minas de Potosí y Huancavelica, ambas sitas en el virreinato del Perú ${ }^{8}$.

Para llevar a cabo esta investigación se han consultado los fondos documentales existentes sobre este tema en el Archivo General de Simancas (sección Consejo y Juntas de Hacienda); en el Archivo Histórico Nacional (sección Consejos Suprimidos) también hay algún legajo sobre el asunto. Acerca de la minería en la España peninsular durante la Edad Moderna en general, hemos consultado el libro clásico de Tomás González ${ }^{9}$ y el de Julio Sánchez Gómez, quien describe con especial énfasis las dos grandes minas de la época: Guadalcanal y Almadén ${ }^{10}$; para la minería de la América colonial en general, los estudios de Carlos Prieto y de Julio Sánchez Gómez ${ }^{11}$; sobre el proceso industrial de la

5 C. Prieto, La minería en el Nuevo Mundo, Madrid, Ediciones de la Revista de Occidente, 1977, pp. 158-162. 6 A. Hernández Sobrino, Los esclavos del rey. Los forzados de Su Majestad en las minas de Almadén, años 1550-1800, Ciudad Real, Fundación Almadén y Asociación Montesur, 1982, pp. 27-173; J. Prior Cabanillas, La pena de minas: Ios forzados de Almadén, 1646-1649, Ciudad Real, Fundación Almadén y Junta de Comunidades de Castilla-La Mancha, 2006, pp. 29-50.

7 A. Matilla Tascón, Historia de las minas de Almadén, vol. II: Desde 1646 a 1799, Madrid, Minas de Almadén y Arrayanes, S.A. e Instituto de Estudios Fiscales, 1987, pp. 65-88.

8 F. Langue y C. Salazar-Soler, Dictionaire des termes miniers en usage en Amerique espagnole (XVI-XIX siecle), Paris, Editions Recherche sur les Civilisations, 1993, pp. 369-375.

9 T. González, Registro y relación general de minas de la Corona de Castilla, Madrid, Imprenta de Don Miguel de Burgos, 1832.

10 J. Sánchez Gómez, De minería, metalurgia..., pp. 417-597.

11 C. Prieto, La minería en el Nuevo..., pp. 51-87; J. Sánchez Gómez, "La técnica en la producción de 
amalgamación, la obra de Manuel Castillo Martos ${ }^{12}$; para la mina de azogue de Almadén, los dos tomos ya citados de Antonio Matilla Tascón, quien ha estudiado su historia hasta el año 1800, y los de Rafael Gil Bautista sobre Almadén en la Edad Moderna ${ }^{13}$; además, para el inicio del XVII es de interés la aportación de Ángel Hernández Sobrino y otros ${ }^{14}$; sobre la utilización de mano de obra forzada en los trabajos mineros, los libros ya citados de Ángel Hernández Sobrino y Julián Prior Cabanillas; para los Fugger en la época de Carlos V, el libro de Ramón Carande; sobre los Fugger en el siglo XVII, el de Pedro Voltes Bou; y sobre el crédito en el reinado de Felipe IV, el de Carlos Álvarez Nogal ${ }^{15}$; y por último, para los forzados y esclavos que había en la Real cárcel de Almadén a finales del XVI, el informe secreto de Mateo Alemán ${ }^{16}$.

\section{LA MINERÍA ESPAÑOLA EN EL TRÁNSITO A LA EDAD MODERNA}

Con los avatares de la Reconquista, la minería española sufrió un considerable retraso respecto a la europea, cuya minería y metalurgia se habían incrementado y mejorado a partir del siglo $X$. Desde dicha centuria, las cuencas mineras alemanas de Goslar y Freiberg producían plomo, plata y cobre, mientras que en el reino de Hungría se extraía oro y en Cornwall (Inglaterra), estaño. En el siglo XIII, la producción de metales de las zonas citadas aumentó considerablemente, a la vez que se descubrían nuevos filones de mineral ${ }^{17}$. Mientras tanto, los Países Bajos y Venecia, situados al norte y al sur de Europa, respectivamente, se convirtieron en los dos centros principales de distribución. No obstante, el comercio de metales sufrió una recesión importante desde mediados del siglo XIV hasta mediados del XV a causa de la depresión económica y del retroceso poblacional causado por las epidemias y las guerras, y el subsecuente descenso de la demanda.

El final de la Edad Media coincidió en Europa con una nueva etapa de intensa búsqueda y puesta en explotación de yacimientos metálicos, de tal forma que el periodo que transcurrió desde 1460 hasta 1540 supuso un auge importante de la actividad minera en Europa Central. Los pozos de extracción fueron cada vez más profundos, superando ampliamente los 200 metros, y el desagüe dejó de ser un gran problema con el uso de la energía hidráulica, con la que se podían mover grandes mecanismos de bombeo. Además se construyeron socavones kilométricos al pie de los montes para que las labores subterráneas desaguaran por su pie. La ventilación de las explotaciones también mejoró mucho, insuflándose aire puro con grandes fuelles movidos por energía hidráulica o animal ${ }^{18}$.

metales monedables en España y en América", en La savia del imperio. Tres estudios de economía colonial, Salamanca, Ediciones Universidad de Salamanca, 1997, pp. 17-264.

12 M. Castillo Martos, Bartolomé de Medina y el siglo XVI. Un sevillano lleva la revolución tecnológica a América, Sevilla, Ayuntamiento de Sevilla, 2001.

13 R. Gil Bautista, Almadén del Azogue, Puertollano, Ediciones Puertollano, 2013; Las minas de Almadén en la Edad Moderna, Publicaciones de la Universidad de Alicante, Alicante, 2015.

14 A. Hernández Sobrino, M. A. Silvestre Madrid y E. Almansa Rodríguez, "La mina de azogue de Almadén en la época del Quijote" en La España del Quijote: IV Centenario Cervantes, Llerena, 2017, Sociedad Extremeña de Historia, pp. 161-172.

15 R. Carande, Carlos V y sus banqueros, Barcelona, Editorial Crítica, 1987; P. Voltes Bou, El ocaso de los Fugger en España. Operaciones de los Fugger en la España del siglo XVII, Ciudad Real, Fundación Almadén, 2009; C. Álvarez Nogal, El crédito de la monarquía hispánica en el reinado de Felipe IV, Ávila, Junta de Castilla y León, 1997.

16 G. Bleiberg, El informe secreto de Mateo Alemán sobre el trabajo forzoso en las minas de Almadén, Londres, Tamesis Book Limited, 1984.

17 J. Sánchez, "La técnica en la producción de metales monedables...", p. 29.

18 J. Sánchez, De minería, metalurgia..., pp. 167-171. 
Entretanto, España había adquirido un enorme retraso en lo que concernía a las técnicas mineras, pero empezó a recuperar el terreno perdido con la llegada a mediados del XVI de técnicas centroeuropeas de la mano de los Fugger. Estos banqueros alemanes, procedentes de Augsburgo, ayudaron económicamente a Carlos I a ser elegido emperador del Sacro Imperio Romano Germánico y, a cambio, tuvieron en asiento, entre otros bienes, la mina de azogue de Almadén de manera prácticamente continua entre 1525 y $1645^{19}$. Por entonces, todo el subsuelo de España era propiedad de la Corona, si bien esta podía arrendar a particulares la explotación de los recursos minerales ${ }^{20}$. Visto el atraso técnico en que se encontraba la minería española, la Corona solicitó a los Fugger que trajeran mineros expertos de Alemania y vinieron unos 200, parte de los cuales fueron enviados a América para desarrollar allí su labor. En 1555 y a miles de kilómetros de distancia iba a ocurrir un hecho trascendental para Almadén, que lo convertiría en una mina de enorme importancia para la Corona: el descubrimiento del método industrial de la amalgamación de los minerales de baja ley con azogue ${ }^{21}$.

Además de los maestros mineros, expertos en oficios tales como la entibación de las labores subterráneas, también llegaron a España y a América técnicos capaces de levantar mapas y planos detallados de pozos, galerías y socavones de mina. Problemas aparentemente tan sencillos como excavar un socavón al pie de una montaña y hacerlo coincidir después de un recorrido de centenares de metros con un pozo vertical situado en la parte alta de aquella, era una verdadera complicación para los veedores ${ }^{22}$ españoles, quienes todavía no sabían usar la brújula en el interior de las minas.

Figura 1. Construcción de un pozo vertical y un socavón horizontal.

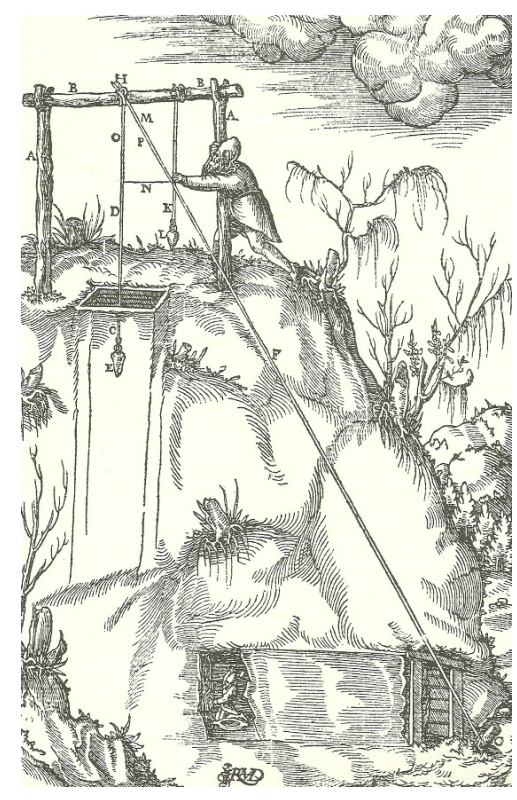

Fuente: Agrícola ${ }^{23}, 1556$.

19 R. Carande, Carlos V y sus banqueros..., p. 371.

20 J. Sánchez, De minería, metalurgia..., p. 204.

21 M. Castillo, Bartolomé de Medina..., pp. 92-113.

22 Personas prácticas e inteligentes en la labor y beneficio de las minas, quienes se encargaban de la supervisión de los trabajos y de los aprovisionamientos necesarios.

23 G. Agrícolae, De Re Metallica libri XII, Basileae: Froben, 1556, p. 130. 
Los Fugger abandonaron Almadén sin haber llegado a utilizar la pólvora para arrancar el mineral, aunque ya era usada en las minas del centro de Europa desde 1620. Por tanto, martillos, picos y cuñas continuaron siendo utilizados por los cuadrilleros, los mineros más jóvenes y fuertes, quienes debían ser sustituidos por otros a los pocos años, ya que el hidrargirismo y la silicosis hacían pronto mella en ellos.

\section{EL OFICIO DE MINERO ENTRE LOS SIGLOS XIII Y XVI}

El trabajo bajo tierra nunca ha tenido muchos demandantes. Si todavía hoy día es poco deseado, mucho menos lo fue en épocas pasadas, en las que el oficio de minero era sinónimo de tinieblas, de sufrimiento e incluso de muerte. En consecuencia resultaba muy difícil encontrar operarios subterráneos, de modo que se hubo de recurrir a trabajadores obligados, fueran mitayos como en las minas andinas, o delincuentes y esclavos como en Almadén, por ejemplo. Otro sistema de conseguir mano de obra fue conceder privilegios a los mineros. En Almadén, ya a mediados del siglo XIII se autorizó a los mineros a “...tomar agua, leña y carbón en los sitios de costumbre y a que su ganado pudiera pastar libremente en los lugares y forma en que se solía hacer"24".

Un siglo después, el problema continuaba sin resolverse, pues la agricultura y la ganadería eran tareas preferidas a las del minero. Por entonces, la Orden de Calatrava continuaba siendo la propietaria de la mina de azogue, si bien arrendaba su explotación a catalanes y genoveses, no tanto porque fueran hábiles mineros, sino porque eran buenos mercaderes que vendían el azogue y bermellón de Almadén dentro y fuera de Castilla. En los arriendos de mediados del siglo XIV, la Orden se comprometió a que si faltasen cuatrelleros $^{25}$ para trabajar en la mina, el arrendatario podría obligar a hacerlo a aquellos vecinos de Almadén que en los últimos tres años hubieran realizado ese trabajo, ".... según la costumbre como fueron apremiados hasta aquí2". Si a esto añadimos que los capataces de los arrendatarios maltrataban frecuentemente a los operarios de la mina, no es de extrañar que la población de Almadén se redujera a una cuarta parte a principios del siglo XIV.

Figura 2. Cuadrillero arrancando el mineral con una maza de hierro de unos $6 \mathrm{~kg}$ de peso.

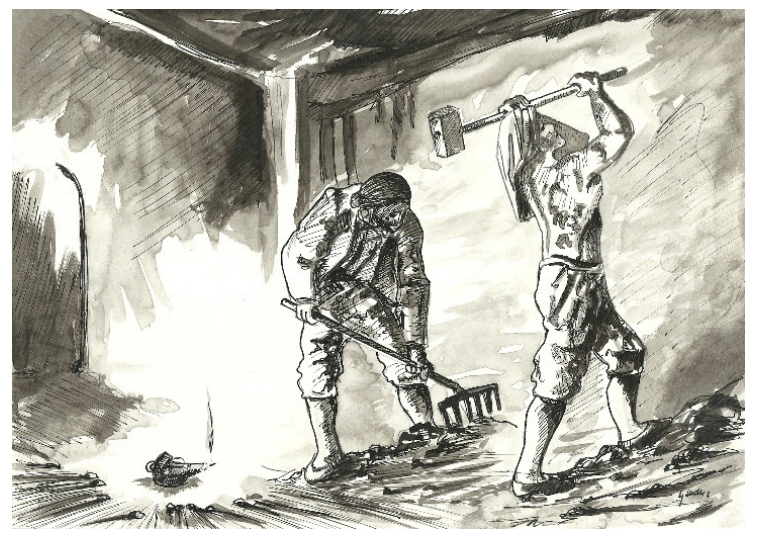

Fuente: J. Calleja, 1998

A principios del siglo XV, Almadén se encontraba tan despoblado que la Orden de Calatrava se vio obligada a concederle lugar exento de su jurisdicción, exceptuando el pago

24 A. Matilla, Historia de las minas de Almadén, Vol. I..., p. 13.

25 Los cuatrelleros o cuadrilleros eran los operarios que arrancaban el mineral del macizo rocoso, labor muy ardua por la dureza de la roca y porque todavía no se usaba la pólvora en Almadén.

26 A. Matilla, Historia de las minas de Almadén, Vol. I..., p. 18. 
de diezmos. El 22 de marzo de 1417, Almadén fue declarado villazgo y los arrendatarios gozaron desde entonces de diversos privilegios y exenciones de alcabalas, portazgos y almojarifazgos. Por su parte, los operarios de la mina tendrían los bastimentos a precio razonable y estarían dispensados de pagar pecho ni tributo alguno al concejo de Almadén. Como la mano de obra libre seguía sin ser suficiente, los arrendatarios solicitaron al maestre de Calatrava que les proporcionase treinta moros durante los seis meses de invierno y quince durante los de verano "...para que hagan pozo de nuevo de que saquemos azogue ${ }^{27 " . ~ A ~}$ cambio, los arrendatarios se comprometían a darles hospedaje y alimentación "...para el dicho mantenimiento a guisa de moro ${ }^{28 "}$.

A partir de 1487, Fernando el Católico quedó como administrador apostólico vitalicio de los bienes y rentas de las Órdenes Militares de Santiago, Alcántara y Calatrava, de modo que la mina de Almadén pasó a ser regida por la Corona. No obstante, la administración regia de la mina de azogue debió durar poco y pronto comenzaron de nuevo los arriendos. Cuando los Fugger arrendaron las dos minas más importantes de España, Almadén y Guadalcanal, se toparon con el mismo problema de la centuria anterior y hubieron de recurrir a mano de obra forzada y esclava. Para la mina de plata de Guadalcanal compraron un centenar de esclavos negros, capturados por los portugueses en África, 86 varones y 14 hembras, pero cuatro años después ya solo quedaban sesenta y nueve y, en 1575, cuando se pensaba ya en abandonar la mina por falta de rentabilidad, había solamente diecinueve esclavos, los cuales fueron trasladados a la mina de Almadén para continuar trabajando en ella ${ }^{29}$.

En el caso de Almadén, los mismos Fugger lo intentaron primero con forzados, delincuentes condenados a las galeras o a las minas, pero como la Corona no enviaba suficientes, recurrieron a la compra de esclavos. Cuando Mateo Alemán fue enviado a Almadén como visitador regio en 1593 debido a las quejas de malos tratos a los forzados, solo encontró en la cárcel de la mina a trece y algunos de ellos enfermos o lisiados, lo que demuestra claramente que la Corona no cumplía lo prometido, ya que en el asiento de 1583 había concedido a los Fugger cuarenta galeotes ${ }^{30}$. Cuando aquellos se ausentaron de Almadén, dejaron en la cárcel a cuarenta y siete esclavos adquiridos a su costa, ya que la Corona siempre dio prioridad al remo en las galeras que al envío de forzados a la mina ${ }^{31}$.

A mediados del siglo XVI, Guadalcanal decayó pero Almadén comenzó a crecer gracias al citado proceso industrial de amalgamación, de modo que la Corona era la primera interesada en incrementar la producción de azogue. No obstante, las dificultades económicas causadas por las guerras imperiales, Flandes sobre todo, impidieron que los mineros de Almadén cobraran puntualmente sus jornales ni que las labores subterráneas fueran debidamente mantenidas. Algunos operarios, quienes llevaban varias semanas sin cobrar sus salarios, abandonaron Almadén y volvieron a sus lugares de origen, y en 1558 hubieron de comprarse 450 fanegas de trigo urgentemente para que a los mineros, al menos, no les faltase el pan. En dicho año y ante tantas dificultades, Ambrosio Rótulo, gobernador de Almadén, solicitó a la Corona por primera vez el envío de treinta delincuentes condenados al remo en las galeras, los cuales parece ser que empezaron a llegar a partir de $1566^{32}$.

27 Ibidem, p. 22.

28 Idem.

29 J. Sánchez, De minería, metalurgia..., pp. 551-557.

30 G. Bleiberg, El informe secreto de Mateo Alemán..., p. 16.

31 Por ello, las minas de azogue fueron conocidas en aquella época como las galeras de tierra, a diferencia de las que navegaban en el Mediterráneo.

32 A. Matilla, Historia de las minas de Almadén, Vol. I..., p. 94. 
Ni los galeotes ni los moriscos, estos últimos obligados después de la rebelión de las Alpujarras a asentarse en Almadén y trabajar en la mina, fueron un recurso suficiente para conseguir la producción necesaria de azogue, y tampoco en la segunda mitad del siglo XVI hubo manera de que los forasteros vinieran a establecerse en Almadén. La situación empeoró y en 1573 se concedió la exención de impuestos a cincuenta vecinos cada año, además de que todos los que trabajaban y servían en la mina quedaban dispensados de ser soldados y de contribuir con sus bagajes y carretas en las guerras o en la conducción de tropas, como sucedió con la guerra con Portugal entre 1580 y $1583^{33}$.

No es de extrañar que los forasteros no quisieran trabajar en la mina de azogue de Almadén porque las labores subterráneas eran nocivas para su salud. Por un lado, al cabo de un tiempo más o menos prolongado mostraban signos de hidrargirismo debido al vapor de mercurio, pero además eran frecuentes la silicosis, producida por el polvo de sílice, y los accidentes. No obstante, la mina contó con la presencia de personal sanitario desde mediados del siglo XVI para atender a los forzados y a los mineros libres: "La enfermería instalada en las dependencias de la cárcel que albergaba a los trabajadores forzados, acabó siendo de uso privativo de estos. Los trabajadores libres recibían en sus domicilios los cuidados de los facultativos de la mina a la vez que solicitaban limosnas para afrontar su subsistencia y el pago de las medicinas necesarias ${ }^{34 " .}$

Como el problema no se había resuelto aún a principios del XVII, el visitador regio Juan de Pedroso propuso en 1613 diversas medidas para conseguir producir 10.000 quintales de azogue al año, pues ni siquiera se conseguían obtener 5.000. En primer lugar, liberar de impuestos no solo a los operarios que había en la mina por entonces, sino también a todos aquellos que vinieran a trabajar en ella; en segundo, que los Fugger, quienes seguían siendo en aquellos años arrendatarios de la mina, prestasen obligatoriamente 60 ducados a cada uno de los 30 vecinos elegidos para que construyeran casas donde poder albergarse adecuadamente; y en tercero, que las pagas fueran puntuales, ya que si les faltaba el sustento los mineros se ausentarían, lo que ya había sucedido en varias ocasiones ${ }^{35}$.

A pesar de los buenos consejos del visitador Pedroso, en la primera mitad del XVII siguieron faltando trabajadores en Almadén, pues los Fugger no consiguieron suficiente mano de obra, ni libre ni forzada. En invierno había más operarios porque el trabajo escaseaba en el campo, pero en la época de cosecha se marchaban de Almadén. Si el año era malo para el campo, había más forasteros que venían a la mina, pues los Fugger les vendían el pan a un precio moderado, para lo que traían trigo de las tierras de los Maestrazgos. El número de operarios variaba en aquella época entre 600 y 1.200, dependiendo de las estaciones, ya que los hornos de tostación del mineral, donde el cinabrio se transformaba en mercurio, solo funcionaban de octubre a abril ${ }^{36}$.

A partir de 1627, la situación comenzó a empeorar por la mala coyuntura de las finanzas de los Fugger, a los que la Corona pagaba tarde, mal y nunca. No obstante, los factores de los Fugger intentaron conseguir atraer gente de los pueblos cercanos a Almadén, ofreciéndoles, además de las exenciones tributarias, dinero prestado y retribuciones más elevadas. Aun así y debido a la falta de dinero en efectivo, en los años anteriores a 1645 los

33 Real Cédula de 24 de enero de 1583. Una sobrecédula de 2 de octubre de 1598 impidió que un agente de reclutamiento sacara de Almadén 24 hombres para ser soldados.

34 A. Menéndez Navarro, Catástrofe morboso de las minas mercuriales de la villa de Almadén del Azogue (1778) de José Parés y Franqués, edición anotada, Ciudad Real, Universidad de Castilla- La Mancha, 1998, p. 27.

35 A. Matilla, Historia de las minas de Almadén, Vol. I..., pp. 129-130.

36 Ibidem, p. 165. 
Fugger tuvieron que pagar los jornales con cédulas. Este sistema perjudicaba gravemente a los mineros, pues los vecinos ricos se las compraban con un tercio de pérdida ${ }^{37}$.

Los negocios de los Fugger con la Corona no se limitaban solamente a los maestrazgos y a la mina de azogue, sino que acudieron muchas veces en ayuda del erario público, ya fuera para la Cruzada, para la Casa Real o con otros fines. La astronómica deuda que acumuló la Corona con los Fugger acrecentó la desconfianza mutua, pues Felipe IV comprendió que no podría contar con ellos para cumplir sus compromisos y los Fugger vieron que todas las medidas que proponían para cobrar la deuda eran rechazadas. El hecho de que en el reinado de Felipe IV más de la mitad de la plata americana se dedicase a cancelar las deudas que la Corona tenía con sus prestamistas, demuestra la gran importancia que tuvieron esos fondos como garantía del crédito de la Monarquía ${ }^{38}$.

A pesar de que la flota de Nueva España naufragó en 1632, arrastrando con ella al fondo del mar entre seis y ocho millones de pesos y dificultando todavía más el cobro de la deuda, los Fugger hicieron un intento desesperado por continuar en Almadén y firmaron un nuevo asiento en 1635. Un grave incendio ocurrido en las labores subterráneas de la Contramina en 1639 empeoró todavía más la situación. No solo fueron los quintales de azogue que dejaron de producirse ni los 38.400 reales que costó la reparación de las explotaciones, sino que además el veedor Antonio Fernández Becerra perdió la vida al intentar apagarlo ${ }^{39}$.

Al final todo se fue al traste y los Fugger se vieron obligados a dejar Almadén. A partir de entonces, la mina de azogue fue explotada en régimen de administración directa por el Consejo de Hacienda y el control de la Corona sobre Almadén se hizo así más estrecho, convirtiéndose en un temprano ejemplo de intervención estatal en actividades productivas ${ }^{40}$. No obstante, la gestión de la Real Hacienda en Almadén durante la segunda mitad del siglo XVII ofreció pobres resultados y los sucesivos administradores tendrían que seguir lidiando con el principal problema del Almadén de aquella época: la falta de operarios para la mina.

\section{REPARTIMIENTO DE MINEROS COMARCANOS}

En la segunda mitad del siglo XVII, España era una nación en declive. Ya habían quedado atrás los reinados de Carlos I y Felipe II, cuando el imperio español brillaba en todo su esplendor. En cambio, Felipe III, Felipe IV y Carlos II mostraron el ocaso de la monarquía de los Habsburgo, a la que Francia, las Provincias Unidas e Inglaterra habían hecho entrar en decadencia. La economía, a pesar de las riquezas del otro lado del Atlántico, era incapaz de hacer frente al oneroso gasto público. Las guerras se llevaron la plata americana y además se perdieron, como sucedió en los Países Bajos y también en Portugal, aunque al menos Felipe IV fue capaz de conservar Cataluña. A la muerte de Felipe IV, el descontento de los españoles aumentó, pues Carlos II no resultó el líder esperado para sacar a nuestro país de su desánimo. En 1662, España suspendió pagos, en 1680 se devaluó la moneda y en 1689 se declaró la guerra a la todopoderosa Francia. Ante tanta ruina y desazón se sucedieron las revueltas populares y hasta el comercio con América se estancó debido a una progresiva decadencia marítima.

37 Ibidem, p. 190.

38 C. Álvarez, El crédito de la monarquía hispánica..., p. 67.

39 Un nieto del citado veedor y también veedor como él hubo de ir a la Corte en 1667 para, en nombre de sus compañeros, solicitar ayuda económica porque no se les abonaban los jornales devengados.

40 R. Dobado González, "Las minas de Almadén, el monopolio del azogue y la producción de plata en Nueva España en el siglo XVIII", en La savia del imperio. Tres estudios de economía colonial, Salamanca, 1997, Ediciones Universidad de Salamanca, p. 405. 
En cuanto a la minería se refiere, la situación también era de paralización, cuando no de retroceso. El yacimiento de plata de Guadalcanal se agotó y en América el Cerro Rico de Potosí producía cada vez menos plata, mientras que las minas de Nueva España todavía no habían desarrollado su gran potencial ${ }^{41}$. Almadén también disminuyó su producción en la segunda mitad de la centuria de 1600, a pesar de que su azogue era un elemento básico para la obtención de plata.

Gráfico 1. Producción de azogue en quintales castellanos entre los años 1551 y 1800.

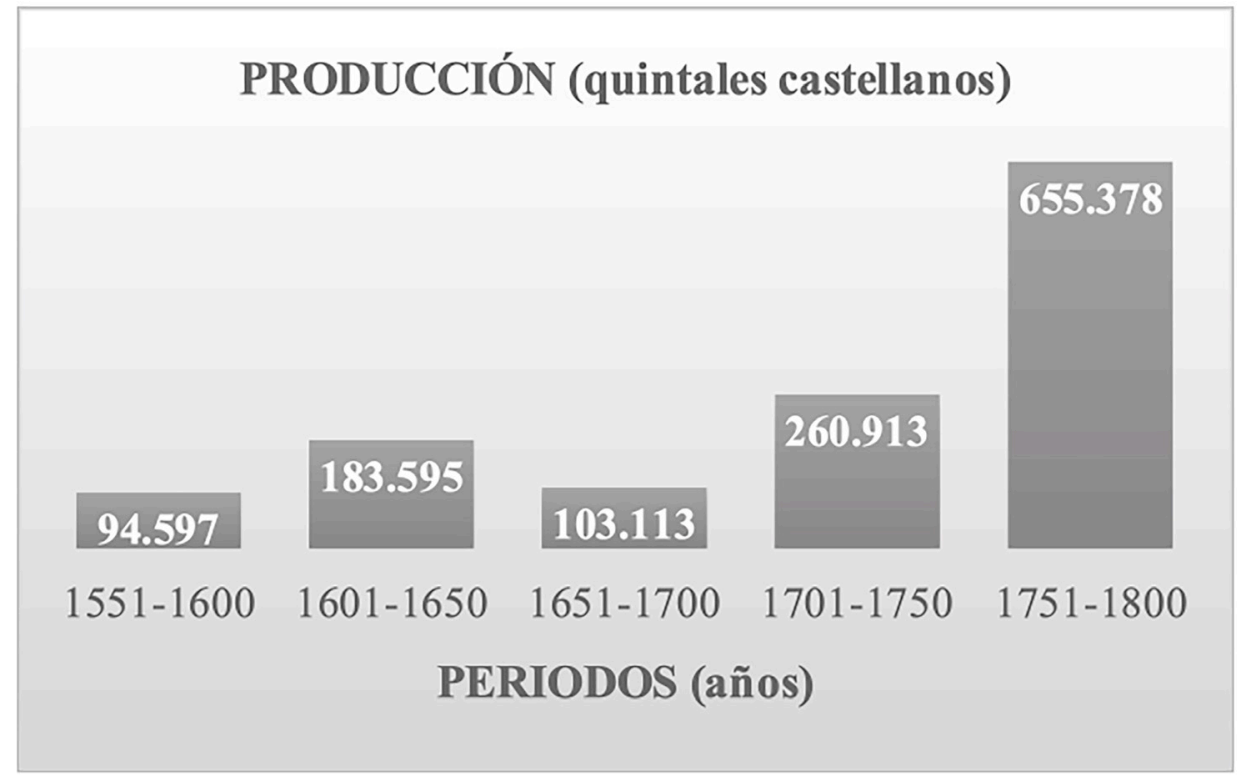

Fuente: elaboración propia a partir de los datos del Archivo Histórico Nacional (AHN), Fondos Contemporáneos-Minas Almadén (FC-MA), legajo 3091.

Otro tipo de dificultades vino a complicar aún más la situación en España, ya que a los diversos brotes epidémicos se sumaron las sequías y heladas que dejaban los campos marchitos. Si bien es cierto que en Almadén las terribles epidemias de peste que se extendieron por la franja mediterránea y por Andalucía occidental en el siglo XVII no costaron muchas vidas, la villa minera padeció una epidemia de tifus en 1736 , en que "...vino sobre la villa del Almadén tan grande contagio de tabardillos, tan malignos, que murieron casi la cuarta parte de moradores de dicha villa... 42". En cuanto a las inclemencias meteorológicas, bien porque no caía una gota de agua, lo más habitual, o porque llevaba siete meses que no había dejado de llover día y noche, la cosecha se echaba a perder la mayoría de los años ${ }^{43}$. Aunque los vecinos recurrieron a implorar la ayuda divina con rogativas y procesiones, "... por la necesidad que hoy tienen los panes y sembrados de agua...", la década de 1670 fue desoladora $^{44}$. Y por último, las plagas de langosta, por ejemplo la de 1669, en la que los jornaleros tuvieron que desplazarse a los lugares por donde avanzaban las langostas para tratar de eliminarlas ${ }^{45}$.

41 Un siglo después, el virreinato de Nueva España se convertiría en el mayor productor mundial de plata.

42 R. Gil Bautista, Almadén del Azogue..., p. 127.

43 Ibidem, p. 110.

44 Ibidem, p. 112.

45 Idem. 
La explotación de una mina como la de Almadén que tiene los bancos de mineral en posición vertical, obligaba a labores subterráneas cada vez más profundas, lo que suponía aumento de las consignaciones económicas para producir la misma cantidad de azogue. Sucedió justo lo contrario, ya que en la segunda mitad del XVII la cobranza de las consignaciones para la mina se hacía con mucho retraso, no pudiéndose abonar el salario a los mineros a su debido tiempo. En 1648 ya se debía a los mineros 627.271 reales, correspondientes a las nóminas de los dos últimos años. El Consejo de Hacienda ordenó que fueran expedidas de manera inmediata libranzas sobre el servicio de millones: Alcázar entregaría anualmente 88.235 reales; Villanueva de los Infantes, 147.059; y Ciudad Real, $352.941^{46}$. Como los pagos se retrasaban, el Consejo ordenó que otros partidos colaboraran también: Córdoba, 27.118 reales; Trujillo, 4.113; Llerena, 15.629; La Serena, 7.903; y Campo de Calatrava, $1.207^{47}$.

Por su parte el marqués de Leganés, general del Ejército de Extremadura, intentaba conseguir todos los fondos posibles para la guerra con Portugal, de modo que los partidos y concejos no sabían a quien debían entregar los impuestos, si al Consejo de Hacienda o al de Guerra. Existen cartas de algunos concejos dirigidas al superintendente de la mina de Almadén, en las que se quejan de los impedimentos puestos por el citado general para entregar a la mina la consignación que tenía en los derechos de millones de dicho lugares ${ }^{48}$. La escasez de numerario continuó en los años siguientes y en 1654, el superintendente Otañez escribió al rey para informarle de las dificultades económicas por las que atravesaba la mina y de la imposibilidad de repararla por falta de recursos ${ }^{49}$. Estas consignaciones fueron aumentando con el paso de los años y en 1688 se estimaba que la mina necesitaba 800.000 reales anuales para pagar los salarios de los mineros y los gastos de explotación del yacimiento ${ }^{50}$.

A pesar de las buenas intenciones del Consejo de Hacienda, el retraso en las consignaciones fue moneda de uso corriente en Almadén. A veces la demora en la paga de los salarios fue tan grande que provocó huelgas de los mineros. Tal es el caso de la sucedida entre el 24 de abril y el 15 de mayo de 1678, cuando los operarios sufrieron un atraso de dieciocho semanas en el cobro de los jornales. Detenidos algunos de los huelguistas, estos dijeron en su defensa que "...nadie habrá quien diga que en caso de tanta estrechez y necesidad con que de presente se halla este lugar, se nos pueda compeler a trabajar sin estipendio ${ }^{51 "}$.

Tres fueron los mecanismos utilizados por superintendentes y administradores para poder hacer más con menos en la mina de Almadén: conseguir que la Corona enviara más forzados a la mina, comprar más esclavos y, por último, el repartimiento de operarios venidos de pueblos cercanos. En cuanto a los forzados, se calcula que en la segunda mitad del XVII, unos 600 cumplieron su condena en los trabajos mineros ${ }^{52}$. Considerando la gravedad de las sentencias, el $14 \%$ fue condenado a diez años, el $6 \%$ a ocho, el 50 $\%$ a seis o cuatro, el $15 \%$ a dos y el $5 \%$ a uno ${ }^{53}$. El $10 \%$ restante fue sentenciado a tres,

46 A. Matilla, Historia de las minas de Almadén, vol. II..., p. 37.

47 Ibidem, p. 38.

48 Archivo General de Simancas (AGS), Consejo y Juntas de Hacienda, legajo 1018.

49 Ibidem, legajo 1022.

50 A. Matilla, Historia de las minas de Almadén, vol. II..., p. 40.

51 AHN, FC-MA, legajo 180.

52 J. Prior, La pena de minas..., p. 101.

53 Ibidem, p. 77. 
cinco y siete años. La ocupación principal de los forzados y esclavos en aquella época fue el desagüe de la mina, considerado uno de los trabajos que mayor esfuerzo exigía y donde aquellos no podían causar ningún incendio ${ }^{54}$. Se calcula que por entonces había un centenar de forzados y esclavos dedicados diariamente a esta labor ${ }^{55}$.

Figura 3. Forzados desaguando las labores subterráneas de la mina de Almadén.

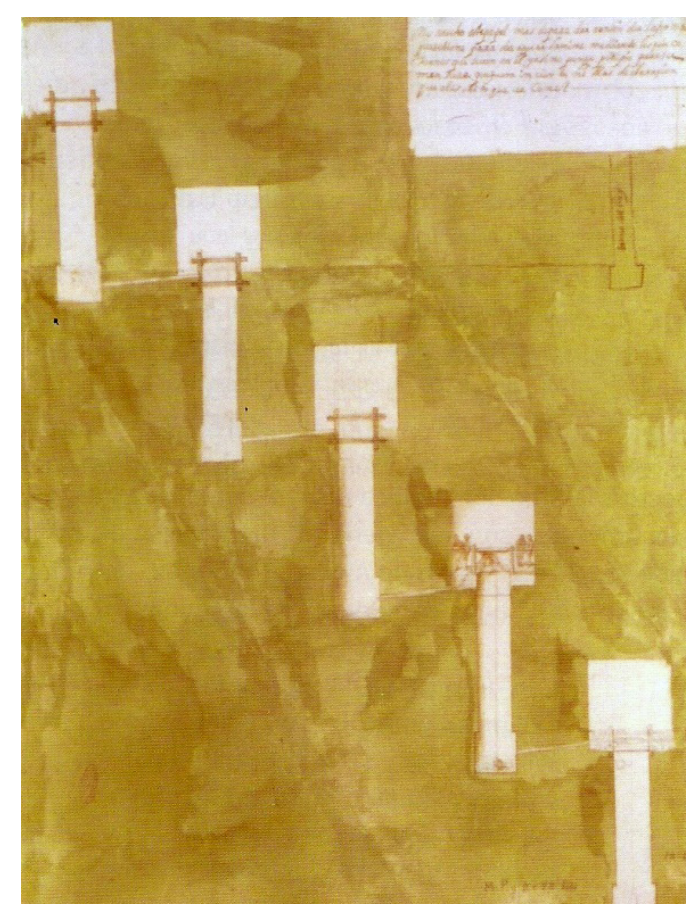

Fuente: AGS, Mapas, planos y dibujos, VII-44

La falta de operarios libres intentó solventarse también con la adquisición de esclavos, mercado muy floreciente en aquellos años. En 1648, el Consejo de Hacienda entregó al conde de Molina 5.500 reales para que comprara esclavos para la mina ${ }^{56}$. Con esta cantidad se podían adquirir por entonces unos 55 esclavos, ya que un esclavo joven y fuerte costaba unos 1.000 reales. No obstante, el conde de Molina continuaba insistiendo en 1649 en la necesidad de más forzados para el desagüe de las labores subterráneas, por lo que solicitó que se enviara a Almadén la décima parte de los condenados a galeras por la Sala del Crimen de la Corte ${ }^{57}$. En 1650, cuando un barco negrero encalló en las costas gallegas, el conde de Molina también pidió que "...se apliquen a la dicha mina los negros que ha aportado un bajel al Reino de Galicia ${ }^{58 " . ~}$

La reposición de mano de obra forzada y esclava era imprescindible, ya que cada año había unos veinte forzados que cumplían su condena o morían en la Real cárcel antes de cumplir su sentencia y además otros se fugaban de un recinto carcelario con poca

54 En varias ocasiones, los forzados y esclavos fueron acusados de ser los culpables de graves incendios en las labores mineras y en consecuencia, no tenían que trabajar.

55 Ibidem, p. 72.

56 AGS, Consejo y Juntas de Hacienda, legajo 952.

57 Ibidem, legajo 953.

58 Ibidem, legajo 963. 
seguridad $^{59}$. En la segunda mitad del XVII se compraron un total de 324 esclavos, no de un modo regular sino en los años en que más escaseaban los forzados y sobre todo en los últimos años de la centuria. En 1697 se descubrió la mina del Castillo, una nueva zona del yacimiento de Almadén, y para su explotación se compraron entre 1697 y 1704 nada menos que 132 esclavos, además de los 148 forzados sentenciados a la mina en dicho período ${ }^{60}$.

Gráfico 2. Número de Esclavos comprados entre 1665 y 1700.

\section{NÚMERO DE ESCLAVOS COMPRADOS}

48

42

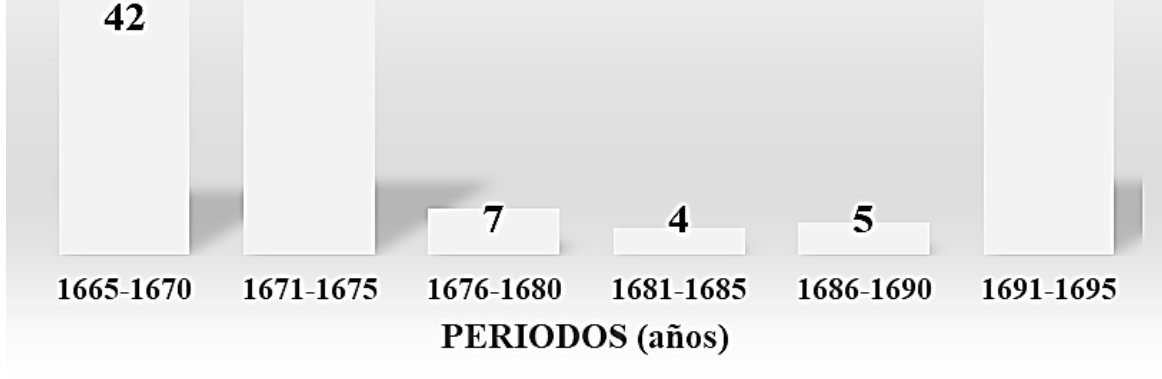

Fuente: elaboración propia a partir de AHN, FC-MA, legajo 1475, caja 1

El tercer método para conseguir brazos para la mina a mediados del XVII fue el llamado de repartimiento, una especie de mita de algunos pueblos cercanos a Almadén a cambio de exenciones militares y fiscales. En el año 1647 se preparaba la conquista de Portugal para responder al atrevimiento del duque de Braganza, quien en 1640 se había proclamado rey de Portugal con el nombre de Juan IV. El conde de Molina, preocupado por lo que la guerra inminente podía suponer para las consignaciones económicas de Almadén, estableció asientos con las villas de Capilla, Garlitos y Peñalsordo, y las aldeas de La Zarza, Baterno y Risco, todas ellas pertenecientes al Estado de Capilla ${ }^{61}$. A cambio de dar 16 peones para trabajar en la mina todos los días y a su costa, las villas y aldeas citadas quedaban exentas de alojar soldados y de contribuir con trigo y cebada para el Ejército de Extremadura ${ }^{62}$. En 1648, el Estado de Capilla solicitó también que se le eximiera del repartimiento de plata para la compra de juros, por ser pobres y tener pocos vecinos ${ }^{63}$. El acuerdo duró desde el año 1648 hasta el $1666^{64}$.

Este sistema de repartimiento ya había sido utilizado por Roma en algunos lugares como un método de contribución de las comunidades indígenas a las explotaciones mineras, sin que el Estado tuviera que mantener así tantos esclavos, los cuales debían ser alimentados y vigilados. También el repartimiento es ciertamente parecido al que se

59 Á. Hernández, Los esclavos del rey..., pp. 133-134.

60 A. Matilla, Historia de las minas de Almadén, vol. II..., p. 83.

61 El llamado Estado de Capilla se halla enclavado en la Siberia extremeña, al noreste de la actual provincia de Badajoz, y las localidades que formaban parte del señorío eran Capilla, Peñalsordo, la Zarza (hoy Zarza Capilla), Garlitos, Risco y Baterno. Esta zona dista de Almadén unos 20 kilómetros hacia el oeste.

62 AGS, Consejo y Juntas de Hacienda, legajo 915.

63 Ibidem, legajo 929.

64 AHN, Consejos Suprimidos, legajo 51.259, 2. 
venía usando en América con el mismo nombre desde el último cuarto del siglo XVI, si bien era conocido también con otros nombres en diferentes regiones: cuatequil en el virreinato de Nueva España, mita en el del Perú, etc. Este tipo de trabajo era libre en cuanto a las personas con quien se ajustaba, mas los indios debían presentarse en los lugares y ejercer el tipo de trabajo exigido por los dueños de las haciendas o las minas. La mita en el virreinato del Perú fue instaurada por el virrey Toledo en 1572 y mediante este sistema funcionaron sus dos minas más grandes: la de plata de Potosí y la de azogue de Huancavelica65.

Figura 4. Territorio del antiguo Estado de Capilla.

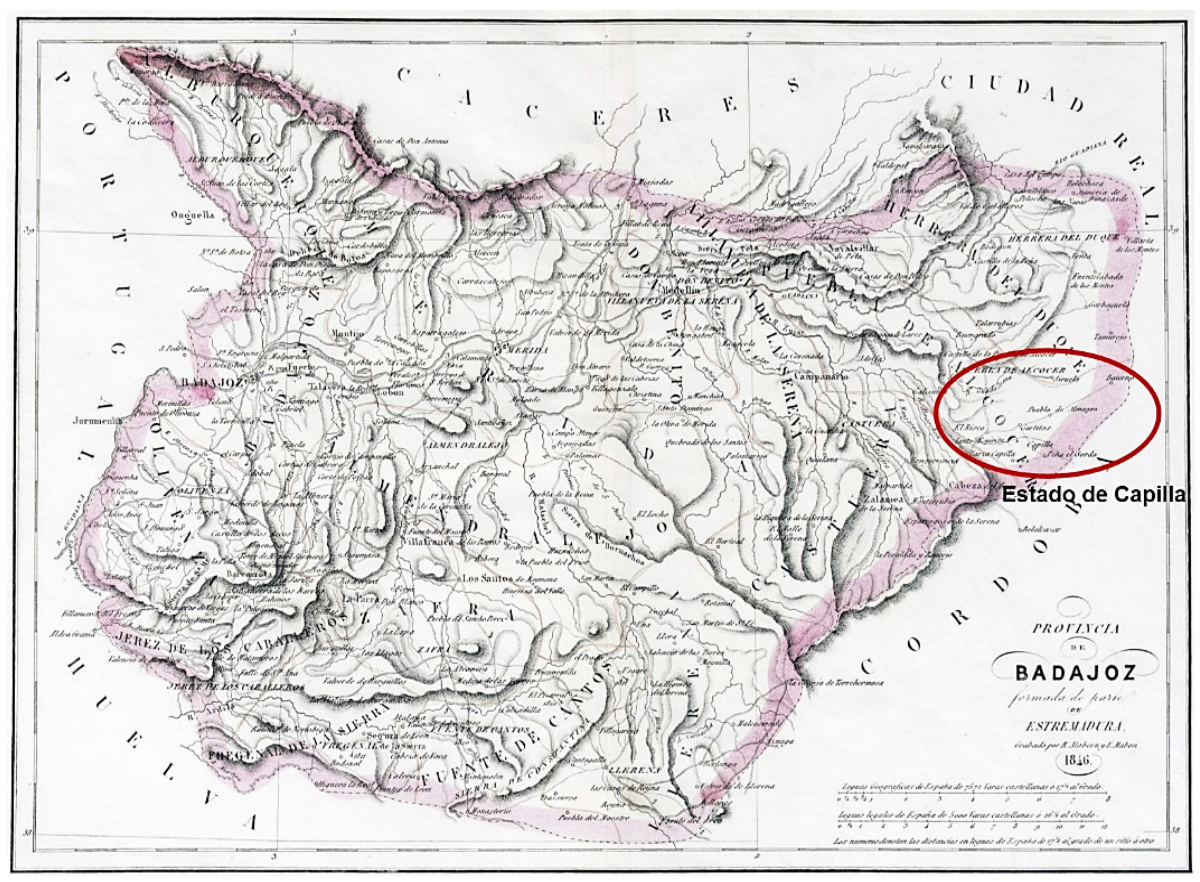

Fuente: elaboración propia a partir del plano dibujado por Mabón y Alabern ${ }^{66}$.

Al igual que ocurría en Almadén, las condiciones de trabajo también eran pésimas en Huancavelica, ya que tanto la seguridad como la higiene de las labores subterráneas no se tenían en cuenta. Hubo accidentes muy graves en los que llegaron a morir más de cien mitayos y era raro el que duraba cinco o seis años sin azogarse, por lo que en ocasiones los indios pagaban para no tener que ir a la mita. Aunque los sucesivos gobernadores de Huancavelica se ayudaron de expertos para la adecuada explotación del yacimiento, el gremio de mineros, para quien trabajaban los mitayos, era muy poderoso y no quería que nadie se inmiscuyera en sus acciones ${ }^{67}$. El sistema de mita fue por fin abolido en 1812.

En España, los ayuntamientos también podían obligar a los vecinos a realizar determinadas tareas por el bien común. Una de ellas, bien conocida, fue la persecución de delincuentes. La Santa Hermandad, debido a la falta de medios, tuvo que recurrir en muchos casos a los alcaldes para que ordenaran a los vecinos que abandonaran sus tareas y les

65 F. Langue y C. Salazar-Soler, Dictionaire des termes miniers..., p. 370.

66 Elaboración propia a partir del plano que lleva por título Provincia de Badajoz formada de parte de Estremadura (sic), dibujado por E. Mabón y R. Alabern (1832-1846) y obtenido de la Cartoteca Histórica Digital de Extremadura (http://sitex.gobex.es/SITEX/pages/cartoteca). Signatura: ES.06800.CHDE.CH009.

67 M. Á. Silvestre Madrid, Mineros de Almadén en la América Colonial, Trabajo Fin de Máster, Universidad de Córdoba, inédito, 2014, p. 34. 
ayudaran a detener a los malhechores. En otros casos, los vecinos eran forzados a luchar contra las plagas de langosta. En la plaga de 1619, miles de hombres fueron obligados a ausentarse durante varias semanas de sus pueblos, llegando a amenazarles con que si desobedecían las órdenes y se volvían a sus casas, podían ser ajusticiados.

Volviendo al sistema de repartimiento, los vecinos del Estado de Capilla se iban alternando para venir a Almadén y dar entre todos 4.480 jornales al año ${ }^{68}$. Algunos otros pueblos copiaron el sistema y la villa de Cabeza del Buey, localidad situada a unos 40 kilómetros al oeste de Almadén, propuso en 1649 y también en 1653 adherirse al convenio a cambio de exención de soldados para el Ejército de Extremadura y de dar alojamiento y provisiones a la milicia. Su petición fue concedida en 1654 y a partir de entonces enviaron a Almadén doce peones diarios y sin sueldo, lo que supuso 3.360 peonadas anuales ${ }^{69}$. Hasta Santa Eufemia, villa perteneciente al Obispado de Córdoba, consiguió la aprobación del asiento por el que quedaba exenta de leva y aprovisionamiento del Ejército a cambio de enviar tres peones diarios a la mina ${ }^{70}$.

El método de repartimiento provocó que el Consejo de Guerra presentara una queja al Consejo de Hacienda por las excusas que presentaban estas villas y lugares para no contribuir con el Ejército de Extremadura ${ }^{71}$. Cuando en alguna ocasión se reclutó a la fuerza a algún vecino de los pueblos citados, la mina realizó las pertinentes diligencias judiciales, como ocurrió con un vecino de la aldea de Risco quien se hallaba preso en Chillón por negarse a ser reclutado ${ }^{72}$.

\section{CONCLUSIONES}

La mina de azogue de Almadén ha sido la mayor del mundo y su gran importancia empezó cuando Bartolomé de Medina descubrió el método de patio, lo que permitió el aprovechamiento de los minerales de plata de baja ley. Las labores subterráneas de Almadén se encontraban a mucha profundidad en el siglo XVII, por lo que la extracción del mineral era muy costosa. Los Fugger se vieron obligados en 1645 a abandonar los asientos de la mina de azogue que venían realizando desde 1525, ya que la Corona no cumplía con sus pagos. Los posteriores administradores españoles, quienes explotaron la mina a partir de entonces, también sufrieron la falta de consignaciones económicas, lo que impidió que se enviara suficiente azogue a las minas de plata americanas. Aunque se intentó conseguir más mano de obra para aumentar la producción, nunca hubo suficientes brazos para el interior de la mina, ya fueran operarios libres o forzados y esclavos.

El trabajo de minero no tenía muchos voluntarios en aquella época y si se trataba de Almadén menos todavía. Los sitios de trabajo se hallaban a más de cien metros bajo tierra y se accedía a ellos por estrechas galerías y pocillos, de modo que la ventilación era muy deficiente. Ello provocaba falta de oxígeno y temperaturas elevadas, lo que dificultaba la respiración de los mineros, quienes se ahogaban en el fondo de este laberinto subterráneo. Por otra parte, los frecuentes accidentes debido a la falta de medios de seguridad y las graves enfermedades profesionales, como el hidrargirismo y la silicosis, todavía complicaban más la situación.

68 Si se daba algún jornal de menos, se debía abonar a la mina seis reales por jornal.

69 AGS, Consejo y Juntas de Hacienda, legajo 1017.

70 AGS, Consejo y Juntas de Hacienda, Cédulas y Provisiones, Real Cédula de aprobación del asiento que se hace con la villa de Santa Eufemia, año 1647, cit. en A. Matilla, Historia de las minas de Almadén, vol. II..., p. 73.

71 AGS, Consejo y Juntas de Hacienda, legajo 1023.

72 Ibidem, legajo 955. 
A mediados del siglo XVII, el conde de Molina, quien había sido enviado como superintendente por la Corona a Almadén, propuso un nuevo método para conseguir más operarios para las minas. Este sistema, aprobado por el Consejo de Hacienda y conocido como repartimiento, ya venía siendo muy utilizado desde el siglo XVI en América colonial para el trabajo de los indios en haciendas y minas. En Almadén se aplicó el método citado y se reclutaron vecinos de algunos pueblos cercanos, quienes se iban turnando para trabajar gratuitamente en la mina a cambio de que sus concejos quedaran exentos de proporcionar hombres y bastimentos al ejército.

A principios del siglo XVIII seguía vigente la exención por privilegio regio de 300 mineros de Almadén. También muchos vecinos de la cercana villa de Chillón y operarios de la mina continuaban dispensados desde 1638 del repartimiento de soldados y otras contribuciones militares. Estas exenciones solo afectaban a los trabajadores que se dedicaban todo el año al oficio de minero y no a aquellos que cuando llegaba la época de siega abandonaban Almadén para dedicarse a las labores del campo.

Lo cierto es que a mediados de la centuria de 1700 la situación había cambiado mucho. En primer lugar, las labores subterráneas eran menos profundas al haberse descubierto a finales del siglo anterior la ya citada mina del Castillo, con lo que la extracción de agua y de mineral era menos costosa; en segundo, la clausura de las galeras del Mediterráneo, pues turcos y berberiscos habían dejado de ser serios enemigos, había causado la llegada a Almadén de numerosos forzados para trabajar en la mina. Ello permitió no tener que comprar esclavos, aunque hubo de construirse una cárcel nueva, mucho más grande, para albergar a tantos forzados; y en tercer lugar comenzó a haber cada vez más forasteros que deseaban asentarse en Almadén y trabajar en la mina, ya que la población española estaba en franco crecimiento y las grandes epidemias de peste del siglo XVII habían desaparecido.

En resumen, la producción de azogue del siglo XVIII triplicó a la del XVII, 916.291 quintales castellanos frente a 286.708, lo que permitió el aprovechamiento de los minerales de baja ley de los yacimientos de Nueva España y, en consecuencia, el desarrollo económico de la América colonial, además del auge y sostenimiento de la monarquía borbónica.

\section{BIBLIOGRAFÍA}

Agricolae, G., De Re Metallica libri XII, Basileae: Froben, 1556.

Álvarez Nogal, C., El crédito de la monarquía hispánica en el reinado de Felipe IV, Ávila, Junta de Castilla y León, 1997.

Bleiberg, G., El informe secreto de Mateo Alemán sobre el trabajo forzoso en las minas de Almadén, Londres, Tamesis Book Limited, 1984.

Carande, R., Carlos V y sus banqueros, Barcelona, Editorial Crítica, 1987.

Castillo Martos, M., Bartolomé de Medina y el siglo XVI. Un sevillano lleva la revolución tecnológica a América, Sevilla, Ayuntamiento de Sevilla, 2001.

Dobado González, R., "Las minas de Almadén, el monopolio del azogue y la producción de plata en Nueva España en el siglo XVIII", en La savia del imperio. Tres estudios de economía colonial, Salamanca, 1997, Ediciones Universidad de Salamanca, pp. 403495.

Gil Bautista, R., Almadén del Azogue, Puertollano, Ediciones Puertollano, 2013.

Gil Bautista, R., Las minas de Almadén en la Edad Moderna, Publicaciones de la Universidad de Alicante, Alicante, 2015.

González, T., Registro y relación general de minas de la Corona de Castilla, Madrid, Imprenta de Don Miguel de Burgos, 1832.

Hernández Sobrino, A., Los esclavos del rey. Los forzados de Su Majestad en las minas de Almadén, años 1550-1800, Ciudad Real, Fundación Almadén y Asociación Montesur, 1982. 
Hernández Sobrino, A., Silvestre Madrid, M. A. y Almansa Rodríguez, E., "La mina de azogue de Almadén en la época del Quijote" en La España del Quijote: IV Centenario Cervantes, Llerena, 2017, Sociedad Extremeña de Historia, pp. 161-172.

Langue, F. y Salazar-Soler, C., Dictionaire des termes miniers en usage en Amerique espagnole (XVI-XIX siecle), Paris, Editions Recherche sur les Civilisations, 1993.

Matilla Tascón, A., Historia de las minas de Almadén, Vol. I: Desde la época romana hasta el año 1645, Madrid, Consejo de Administración de Minas de Almadén y Arrayanes, 1958.

Matilla Tascón, A., Historia de las minas de Almadén, vol. II: Desde 1646 a 1799, Madrid, Minas de Almadén y Arrayanes, S.A. e Instituto de Estudios Fiscales, 1987.

Menéndez Navarro, A., Catástrofe morboso de las minas mercuriales de la villa de Almadén del Azogue (1778) de José Parés y Franqués, edición anotada, Ciudad Real, Universidad de Castilla- La Mancha, 1998.

Prieto, C., La minería en el Nuevo Mundo, Madrid, Ediciones de la Revista de Occidente, 1977.

Prior Cabanillas, J., La pena de minas: Ios forzados de Almadén, 1646-1649, Ciudad Real, Fundación Almadén y Junta de Comunidades de Castilla-La Mancha, 2006.

Sánchez Gómez, J., De minería, metalurgia y comercio de metales. La minería no férrica en el reino de Castilla, 1450-1610, Salamanca, Universidad de Salamanca e Instituto Tecnológico GeoMinero de España, 1989.

Sánchez Gómez, J., "La técnica en la producción de metales monedables en España y en América", en La savia del imperio. Tres estudios de economía colonial, Salamanca, Ediciones Universidad de Salamanca, 1997, pp. 17-264.

Silvestre Madrid, M. Á., Mineros de Almadén en la América Colonial, Trabajo Fin de Máster, Universidad de Córdoba, inédito, 2014.

Voltes Bou, P., El ocaso de los Fugger en España. Operaciones de los Fugger en la España del siglo XVII, Ciudad Real, Fundación Almadén, 2009. 